\title{
Activity Assessment of Tunisian Olive Leaf Extracts Against Survival and Virulence in vitro of Candida glabrata
}

\author{
S. Abbes ${ }^{1 *}$, I. Amouri ${ }^{1}$, H. Trabelsi ${ }^{1}$, S. Neji ${ }^{1}$, H. Chelly ${ }^{1,2}$, H. Sellami ${ }^{1}$, F. Makni ${ }^{1}$ and Ayadi $A^{1}$ \\ ${ }^{1}$ Laboratoire de biologie moléculaire parasitaire et fongique, faculté de médecine-Université de Sfax-Tunisie \\ ${ }^{2}$ Service de réanimation, Hôpital Habib Bourguiba, Sfax-Tunisie
}

Received: September 16, 2016; Accepted: October 26, 2016; Published: November 1, 2016

*Corresponding author: Abbes Salma, Laboratoire de biologie moléculaire parasitaire et fongique, Faculté de médecine -Sfax-Tunisie. Code postal, 3029. Tel: +21622629658; E-mail: sel_salma@yahoo.fr

\begin{abstract}
C. glabrata has become a prominent pathogen less susceptible to azole antifungal agents when compared with other Candida spp.

Aims: Our work aimed to study some virulence factors of $C$ glabrata isolates and to test the activity of Chemlali Olive Leaf Extract (OLE) against virulence and the survival of clinical C. glabrata isolates.

Methods: The virulence factors of a collection culture of $C$. glabrata isolated from blood culture $(\mathrm{n}=35)$, vulvovaginal $(\mathrm{n}=21)$, and buccal site $(\mathrm{n}=5)$ were analyzed in specific medium with and without OLE.

Results: All C. glabrata isolates tested were able to produce haemolysin and to form biofilm ( $\mathrm{n}=61), 98.3 \%$ of isolates were phospholipase producer and $96.7 \%$ were protease producer. No significant difference between $\mathrm{Pz}$ values was obtained from oral cavity, vulvovaginal and blood culture isolates ( $p$ value $\geq 0.05$ ). $C$. glabrata growth was dramatically decreased after treatment with olive leaves extract and exhibited $\mathrm{MIC}_{90}$ value in the range of 2-8 $\mathrm{mg} / \mathrm{ml}$ and MFC value range from 16 to $32 \mathrm{mg} / \mathrm{ml}$. There was a significant $(p<0.05)$ decrease observed in Pz value in the test strains of $C$. glabrata treated with $0.25 \mathrm{xMICs}$ of olives leaves compared to untreated control at equal cell density. OLE was able to reduce in vitro proteinase production by an average of $55.87 \%$, by $46.85 \%$ for phospholipase activity, by $25.37 \%$ for haemolysin activity and only $2.43 \%$ to $39.13 \%$ biofilm formation was recorded.
\end{abstract}

Conclusion: C. glabrata isolates from Sfax University Hospita presented a high virulent power and these activities do not depend on the sampling sites but on possible evolutionary changes that may occur between different regions of the world. Olive leaves extract evaluated here is a potential therapeutic drug for the treatment of C. glabrata infection not only in the growth but also in inhibition of virulence factors.

Keys words: Candida glabrata; Virulence factors; Olive leaves extract; Antifungal drugs

\section{Introduction}

C. glabrata has become a prominent pathogen causing invasive candidiasis infections at our institution. It was the third most common member of the genus isolated [1] and is of interest because it is less susceptible to azole antifungal agents, especially to fluconazole, when compared with other Candida spp. The therapy of this type of fungemia has been undetermined by resistance, variable efficacy between strains or species, toxicity, and requirement for long courses of treatment. A need for identifying alternative natural and safe sources of molecules, especially of plant origin, to treat these diseases has notably increased in recent years [2]. Recently, several studies focused on high-added-value compound of the Olive Leaves Extract (OLE) [3-5]. The Olive plant leaves are used in folk medicine as a remedy for eye infections, sore throat, urinary tract infections, kidney problems and backaches or headaches. It is also used as a hypotensive, emollient, febrifuge and styptic [6]. The leaves of the tree were reported to be potent for the treatment of malaria in 1854 [7]. Olive oil occupies also an important place in the Mediterranean diet due to its nutritional and dietetic qualities and the Chemlali variety from Sfax region had excellent nutritional characteristics in terms of sterol, aliphatic alcohol, and tocopherol content [8]. In the present study, we investigate the activity of Chemlali olive leaf cultivar against virulence and the survival of clinical C. glabrata isolates from blood culture, vulvovaginal, and buccal site.

\section{Materials and Methods}

\section{Patients and isolates}

Sixty one C. glabrata clinical isolates were collected from 46 patients from different anatomical sites. Thirty five strains were isolated from Blood Culture (BC) and five isolates from oral site. Eleven C. glabrata strains isolated from three or more consecutive episodes of Candida glabrata vaginitis obtained from patients with RVVC (Recurrent vulvovaginal Candidiasis). Additionally, 10 patients who had experienced a single episode of VVC (Vulvovaginal Candidiasis) in a 1 year period were analyzed; two reference strain C. glabrata ATCC90020 and CBS138 and one $C$. albicans reference strains ATCC90028 were included as controls in the present investigation. All the blood specimens from the patients were inoculated into Bactec PED bottles (Becton-Dickinson, USA), which were incubated in the Bactec ${ }^{R}$ 
9050 automated culturing system (BD diagnostic Systems 9050, Oxford, UK) at $37^{\circ} \mathrm{C}$ for 15 days or until the bottles were positive by the colorimetric detection of $\mathrm{CO}_{2}$ and vaginal and oral sampling were carried out through sterile swabs. Yeasts grown on SDA plates (Sabouraud Dextrose Agar) at $37^{\circ} \mathrm{C}$ for Candida species were identified according to their morphological characteristics and biochemical profiles. To identify the isolates they were inoculated onto Candiselect ID medium (Bio-Rad, France) and incubated at $37^{\circ} \mathrm{C}$ for 48 h. C. glabrata was initially identified by the green color of its colonies, which was subsequently confirmed by ID32C (Biomérieux, France) assimilation test and GLABRATA RTT (Fumouze Diagnostic, Paris France) and the susceptibility to fluconazole was determined by measuring the Minimum Inhibitory Concentration (MIC) obtained through the use of the E-test (Biomérieux, France).

\section{Preparation of Olive Leaves Extracts (OLE)}

Plant material of Chemlali variety collected from Sfax region, Tunisia, was used as sample for our investigation. Leaves $(1 \mathrm{~g})$ were homogenized and extracted over night at $32^{\circ} \mathrm{C}$ with $20 \mathrm{ml}$ of methanol (ProLABO, Paris) in a capped glass tube on an agitating plate at a constant stirring rate $(280 \mathrm{rpm})$.

The crude extracts were concentrated in a rotary evaporator and then transferred into sterile vials with $10 \mathrm{ml}$ of DMSO (1\%) and finally were kept under refrigerated conditions until further use $[9,10]$.

\section{Detection of virulence factors in isolates of Candida glabrata}

Proteinase assay: Production of extracellular proteinase was assessed by the method of Aoki, et al. [11] using BSA agar plates. Briefly, $60 \mathrm{~mL}$ of a solution containing $\mathrm{MgSO}_{4} \cdot 7 \mathrm{H}_{2} \mathrm{O} 0.04$ $\mathrm{g}, \mathrm{K}_{2} \mathrm{HPO}_{4} 0.5 \mathrm{~g}, \mathrm{NaCl} 0.2 \mathrm{~g}$, yeast extract $0.2 \mathrm{~g}$, glucose $4.0 \mathrm{~g}$ and Bovine Serum Albumin (BSA) (Sigma, USA) 0.5 g; was prepared and the $\mathrm{pH}$ was adjusted to 3.5 with $1 \mathrm{~N}$ of HCL. This solution was filter sterilized and mixed with $140 \mathrm{ml}$ of autoclaved melted agar to prepare the BSA agar plates.

Amounts of $10 \mu \mathrm{L}$ of yeast suspension $1.10^{6} \mathrm{cfu} \cdot \mathrm{mL}^{-1}$ (Colony Forming Unit) were spot inoculated on the BSA agar plates and incubated at $37^{\circ} \mathrm{C}$ for 5 days. After incubation, the plates were stained with $0.1 \%$ amido black dye and destained with $15 \%$ acetic acid, and the clear zone was measured.

$\mathrm{Pz}$ values were calculated in terms of the ratio of the diameter of the colony to the total diameter of colony plus zone of solubilization as described by Price, et al. [12]. The enzymatic activity was scored into four categories, a Pz of 1.0 indicated no enzymatic activity; a Pz between 0.99 and 0.90 indicated low enzymatic activity; Pz between 0.89 and 0.70 corresponded to moderate activity; and low Pz values < 0.69 meant high enzymatic activities. The Candida albicans ATCC 90028 strains was used as a positive control.

Hemolysis assay: Haemolysin production was evaluated using a modified method of Luo, et al. [13]. The blood agar plates were prepared by adding $7 \mathrm{ml}$ of fresh sheep blood suspended in sterile Phosphate Buffer Saline (PBS) to $100 \mathrm{~mL}$ of SDA supplemented with $3 \%(\mathrm{w} / \mathrm{v}$ ) glucose. Amounts of $10 \mu \mathrm{l}$ of yeast suspension $1.10^{6} \mathrm{cfu} . \mathrm{mL}^{-1}$ were spot inoculated on the blood agar plates and incubated at $37^{\circ} \mathrm{C}$ for $48 \mathrm{~h}$. After incubation, plates were scored for the presence of translucent ring and or a greenish black halo circumscribing the inoculum growth. Haemolysin activity (Pz values) was calculated in terms of the ratio of the diameter of the colony to the total diameter of colony plus zone of halo using the method described by Price, et al. [12].

Phospholipase production: Phospholipase activity of Candida species were detected by egg yolk agar plate method [12]. The egg yolk medium consisted of $13.0 \mathrm{~g}$ SDA (Scharlau, Spain), $11.7 \mathrm{~g} \mathrm{NaCl} 0.11 \mathrm{~g} \mathrm{CaCl}_{2}$ and $10 \%$ sterile egg yolk. A loopful of an overnight yeast culture approximately $1.10^{6} \mathrm{cfu} . \mathrm{mL}^{-1}$ determined through densitometer was aseptically inoculated onto the medium and incubated at $37^{\circ} \mathrm{C}$ for 5 days. Phospholipase activity was calculated in terms of the ratio of the diameter of the colony to the total diameter of colony plus zone of halo using the method described by Price, et al. [12]. The Candida glabrata ATCC CBS138 strain was used as a positive control.

Biofilm formation in vitro and biomass quantification: For each experiment, strains were subcultured on Sabouraud Dextrose Agar (SDA) for $48 \mathrm{~h}$ in $37^{\circ} \mathrm{C}$. Cells were then suspended in YPG medium (1\%Yeast, 1\%Peptone, 2\%Glucose) and the cellular density was adjusted to $1.10^{6} \mathrm{cfu} \cdot \mathrm{mL}^{-1}$ using a densitometer.

Standardized cell suspensions $\left(200 \mu \mathrm{l}\right.$ containing $1.10^{6}$ cfu.mL $\mathrm{m}^{-1}$ in SDA) were placed into selected wells of 96-well polystyrene microtiter plates (Kartell. SPA, Italy) and incubated in $37^{\circ} \mathrm{C}$ on a shaker at $120 \mathrm{rpm} / \mathrm{min}$. At $24 \mathrm{~h}, 50 \mu \mathrm{l}$ of fresh YPG medium was added. The preparations were then incubated for a further $24 \mathrm{~h}$. After this step, the medium was aspirated and non-adherent cells removed by washing the biofilms twice with sterile ultra-pure water [14].

Quantification of total biomass by Crystal Violet (CV) (PARK inc, Northampton UK staining), after washing, biofilms were fixed with $200 \mu \mathrm{l}$ of methanol, which was removed after $15 \mathrm{~min}$ of contact. The microtiter plates were dried at room temperature, and $200 \mu \mathrm{l}$ of $\mathrm{CV}(1 \% \mathrm{v} / \mathrm{v})$ added to each well and incubated for $5 \mathrm{~min}$. The wells were then gently washed with ultra-pure water. The absorbance of the obtained solutions was read in three separate experiments in a microtiter plate reader (Bio-Tek Synergy HT, Izasa, Lisbon, Portugal) at $620 \mathrm{~nm}$.

Antimicrobial assay (Disc diffusion assay): The crude extracts were dissolved in dimethyl sulfoxyde (DMSO 1\%), to a final concentration of $30 \mathrm{mg} / \mathrm{mL}$ and sterilized through filtration by $0.45 \mu \mathrm{m}$ Millipore filters. Antifungal tests were then carried out by the disc diffusion method [15] using $200 \mu \mathrm{l}$ of suspension containing $1.10^{6}$ cfu.mL ${ }^{-1}$ of yeast, spread on SDA medium. The discs (6 $\mathrm{mm}$ in diameter) were impregnated with $10 \mu \mathrm{l}$ of extracts placed on the inoculated agar. Negative controls were prepared using DMSO (1\%) used to dissolve the plant extracts. The inoculated plates were incubated at $37^{\circ} \mathrm{C}$ for $48 \mathrm{~h}$.

Determination of Minimal Inhibitory Concentration (MIC) and Minimal Fungicidal Concentration (MFC)

The MIC and MFC determinations were measured according 
to modified methods described by Sahin, et al. [16]. Leaf extract was diluted with same solvents to produce two-fold serial dilutions ranging from 0.5 to $32 \mathrm{mg} / \mathrm{ml}$. From each prepared solutions $1 \mathrm{ml}$ was added into test tubes containing $5 \mathrm{ml}$ YPG broth. Yeasts suspensions ( $1 \mathrm{ml}$ ) prepared from $24 \mathrm{~h}$ YPG broth cultures and adjusted to $0.5 \mathrm{McF}$ arland turbidity, were added to the tubes containing olive leaf extracts or solvent used as control. Test tubes were then incubated at $37^{\circ} \mathrm{C}$ for $48 \mathrm{~h}$. Determination of the total viable cells was performed using YPG plate count agar, which were inoculated with serial dilutions and incubated at $37^{\circ} \mathrm{C}$ for $48 \mathrm{~h}$. Countable plates are those containing from 0 to 250 colonies [17]. The $\mathrm{MIC}_{50}$ and $\mathrm{MIC}_{90}$ of the test extracts were the lowest concentration of extracts that did permit only $50 \%$ and $10 \%$ respectively of cells to survive. The MFC was defined as the lowest concentrations that completely inhibit the growth of yeasts in YPG plates at $37^{\circ} \mathrm{C}$ for $48 \mathrm{~h}$.

Determination of viability of Candida glabrata strains at sub-MICs of olive leaf: The test strains at a cell density of $1.10^{6}$ cfu.mL-1 were inoculated into test tubes containing $10 \mathrm{ml}$ of YPG amended with sub-MICs $(0.25 \times$ MICs $)$ of test agents for $24 \mathrm{~h}$ at $37^{\circ} \mathrm{C}$. A control was run without test agents but containing yeast inoculum at equal cell density. Viable counts were obtained from the test and control solutions by plating $100 \mu \mathrm{L}$ of 10 -fold serial dilutions onto SDA plates and incubating at $37^{\circ} \mathrm{C}$ for $24 \mathrm{~h}$.

\section{Inhibition of virulence factors by olive leaves at sub- MICs}

Inhibition of proteinase production: Briefly, BSA agar plates amended with sub-MICs $(0.25 \times$ MIC) of OLE and fluconazole were inoculated with $100 \mu \mathrm{L}$ of Candida glabrata cells $\left(1.10^{6} \mathrm{cfu} . \mathrm{mL}-1\right)$ and incubated at $37^{\circ} \mathrm{C}$ for 7 days. Proteinase production was determined in terms of the ratio of the diameter of the colony to the total diameter of colony plus zone of halo using the method described by Price, et al. [12]. The inhibition of proteinase production by olive leaves was determined as $\mathrm{R}=(\mathrm{Pz}$ in treated sample $-\mathrm{Pz}$ untreated sample). A ratio $=0$ indicated no inhibition of enzymatic activity and $\mathrm{R}>0$ indicated inhibition of proteinase activity. Each experiment was conducted three times with three replicates per experiment.

Inhibition of haemolysin production: Candida glabrata cells were grown in blood agar plates as previously described containing $0.25 \times \mathrm{MIC}$ of test agents for 4 days at $37^{\circ} \mathrm{C}$. The solution without test agents was considered as untreated control. Each experiment was conducted three times with three replicates per experiment. The inhibition of hemolysin production by olive leaves extract was determined as $\mathrm{R}=(\mathrm{Pz}$ in treated sample $-\mathrm{Pz}$ untreated sample). A ratio $=0$ indicated no inhibition of enzymatic activity and $\mathrm{R}>0$ indicated inhibition of haemolysin activity.

Inhibition of phospholipase production: Candida glabrata cells were grown in egg yolk medium as previously described containing $0.25 \times \mathrm{MIC}$ of test agents for 5 days at $37^{\circ} \mathrm{C}$. The solution without test agents was considered as untreated control. Each experiment was conducted three times with three replicates per experiment. The inhibition of phospholipase production by olive leaves extract was determined as $\mathrm{R}=(\mathrm{Pz}$ in treated sample
- Pz untreated sample). A ratio $=0$ indicated no inhibition of phospholipase activity and $\mathrm{R}>0$ indicated inhibition of activity.

\section{Inhibition of biofilm formation by olive leaf extract at sub-MICs}

Effect of olive leaf extract on biofilm formation: The effect of different sub-MICs of OLE and fluconazole (0.25 × MIC) on the ability of Candida glabrata to form biofilm was determined as previously described with some modifications. Volumes of 0.1 $\mathrm{mL}$ of test agents $(2 \times$ final concentrations $)$ in YPG medium was added to each well of microtiter plates. Subsequently, $0.1 \mathrm{~mL}$ of standardized yeast cell suspension was added and plates were incubated at $37^{\circ} \mathrm{C}$ for $48 \mathrm{~h}$. Antifungal agent-free wells served as positive controls for biofilm growth. After incubation, the medium and non-adherent cells were removed from wells and washed three times with sterile PBS. Further biofilm formation was analyzed by $\mathrm{CV}$ reduction assay. Absorbance values were used to measure the inhibition of biofilm formation as follows: (mean $\mathrm{OD}_{620}$ of treated well/ mean $\mathrm{OD}_{620}$ of untreated control well) $\times 100$.

Statistical analysis: All the experiments were performed three times with three replicates per experiment and data are expressed as mean \pm standard deviation. Statistical significance of the differences was determined by using Student's t-test (SPSS version 13.0) and ANOVA test. Differences were considered significant at $p \leq 0.05$. All in vitro experiments were performed respectively at least three times.

\section{Results}

\section{C. glabrata virulence factors: extracellular hydrolases and biofilm formation}

We collected 61 C. glabrata isolates from blood samples, buccal and vaginal site. All isolates were tested for susceptibility to fluconazole. All isolates have a high susceptibility to Fluconazole $\left(\mathrm{CMI}_{90}=0.25\right.$ to $\left.8 \mu \mathrm{g} / \mathrm{ml}\right)$. Moreover three isolates showed in vitro resistant profile $\left(\mathrm{CMI}_{90}>64 \mu \mathrm{g} / \mathrm{ml}\right)$.

We investigated in the present study in vitro virulence factors of 61 Candida glabrata isolates [Figure 1]. The production and quantitative expression of these factors in different $C$. glabrata isolates were recapitulated in Table1. All tested C. glabrata isolates were able to produce haemolysin with an average $\mathrm{Pz}$ mean $(0.684 \pm 0.118)$ and to form biofilm $\left(A_{620}=0.3 \pm 0.42\right)$, $98.3 \%$ of isolates were phospholipase producer with an average

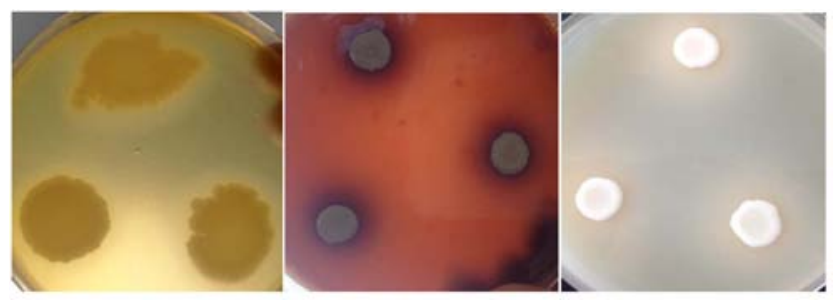

Figure 1: Culture of isolates of C. glabrata in medium rich on egg yolk $(10 \%)(A)$, on blood agar plate (5\%) (B) and BSA (1\%) (C). A white halo around the colonies indicate an enzymatic production. 
Table 1: Level of phospholipase, haemolysin and protease production by Candida glabrata isolates from blood culture, vaginal and buccal sites

\begin{tabular}{|c|c|c|c|c|c|c|c|c|c|c|}
\hline & & \multicolumn{3}{|c|}{$\begin{array}{l}\text { Phospholipase activity } \\
\text { (number of isolates/ rate of isolates) }\end{array}$} & \multicolumn{3}{|c|}{$\begin{array}{l}\text { Haemolysin activity } \\
\text { (number of isolates/ rate of isolates) }\end{array}$} & \multicolumn{3}{|c|}{$\begin{array}{l}\text { Protease activity } \\
\text { (number of isolates/ rate of } \\
\text { isolates) }\end{array}$} \\
\hline & & $\begin{array}{l}\text { Blood culture ( } \mathrm{n} \\
=35 \text { ) }\end{array}$ & $\begin{array}{l}\text { Vaginal } \\
(\mathrm{n}=21)\end{array}$ & $\begin{array}{l}\text { buccal } \\
(\mathrm{n}=5)\end{array}$ & $\begin{array}{l}\text { Blood } \\
\text { culture } \\
(n=35)\end{array}$ & $\begin{array}{l}\text { Vaginal } \\
(\mathrm{n}=\mathbf{2 1})\end{array}$ & $\begin{array}{l}\text { buccal } \\
(\mathrm{n}=5)\end{array}$ & $\begin{array}{l}\text { Blood } \\
\text { culture } \\
(n=35)\end{array}$ & $\begin{array}{l}\text { Vaginal } \\
(\mathrm{n}=\mathbf{2 1})\end{array}$ & $\begin{array}{l}\text { buccal } \\
(n=5)\end{array}$ \\
\hline \multirow{4}{*}{ 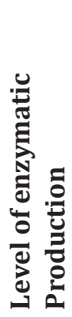 } & Strong & $16(45.7 \%)$ & 7(33.3\%) & $2(40 \%)$ & $16(45.7 \%)$ & 11(52.3\%) & $3(60 \%)$ & $33(94.2 \%)$ & 19(90.4\%) & $5(100 \%)$ \\
\hline & Moderate & $19(54.2 \%)$ & $13(61.9 \%)$ & $3(60 \%)$ & 19(54.2\%) & $10(47.6 \%)$ & $2(40 \%)$ & $1(2.8 \%)$ & $1(4.7 \%)$ & 0 \\
\hline & Weak & 0 & 0 & 0 & 0 & 0 & 0 & 0 & 0 & 0 \\
\hline & nul & 0 & $1(4.7 \%)$ & 0 & 0 & 0 & 0 & $1(2.8 \%)$ & $1(4.7 \%)$ & 0 \\
\hline
\end{tabular}

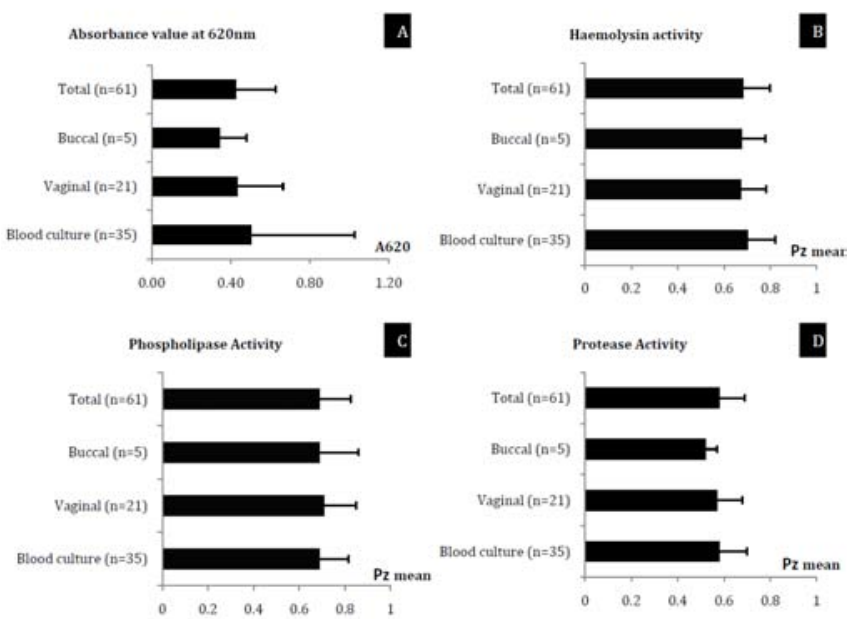

Figure 2: The distribution of biofilm formation (A), haemolysin activity (B), phospholipase activity (C) and protease activity (D) among blood culture, vaginal and buccal clinical isolates.

production $(\mathrm{Pz}=0.69 \pm 0.13)$ and $96.7 \%$ were protease producer with an average production $(\mathrm{Pz}=0.58 \pm 0.11)$.

The average production for invasive C. glabrata isolates was $(\mathrm{Pz}=0.58 \pm 0.12)$ for protease activity, $(\mathrm{Pz}=0.704 \pm 0.118)$ for haemolysin activity and $(\mathrm{Pz}=0.69 \pm 0.126)$ for phospholipase activity [Figure 2].

Relationship between the average Pz values of phospholipase activity, protease activity, hemolysin activity and the infection sites were demonstrated in figure 2. The One Way ANOVA test showed a non significant difference in haemolysin, phospholipase and protease activity between oral cavity, vulvovaginal and blood culture isolates $(p \geq 0.05)$.

Biomass quantification results of the in vitro biofilm formation are shown in Figure 2A. The amount of biofilm formed in each case was estimated in triplicate and an average was calculated for each isolate. The amount of obtained biomass were $\left(A_{620}, 0.503 \pm 0.522\right)$ for invasive isolates, (Abs moy, $0.43 \pm 0.23$ ) for vaginal isolates (Abs moy, $0.344 \pm 0.13$ ) for buccal isolates. For each strain, a small change in Abs ${ }_{(620 \mathrm{~nm})}$ value was noted. It was noted that the total amount of biomass formed in vitro by invasive isolates was slightly higher than that formed by vaginal and buccal. However, this difference was proven insignificant ( $p$ value $\geq 0.05$ ). The highest level of absorbance was observed for two invasive isolates $211 \mathrm{BC}$ and $362 \mathrm{BC}\left(\mathrm{Abs}_{620} 2.8 \pm 0.19\right.$ and 2.1 \pm 0.21 respectively) which formed a biomass amount high as 9 and 7 folds.

\section{Olive Leaves Extract (OLE) and antifungal activity}

In the present study, olive leaf extracts of Chemlali variety were screened for their activity against some C. glabrata isolates. A collection of isolates (C. glabrata ATCC 90020, 211BC, 636BC, 603BC, 362BC, 375VVC and 51VVC) were selected on the basis of being producers of an important amount of proteinase, phospholipase and/or haemolysin and biomass in polystyrene plate from two independent experiments. Selected isolates were inoculated in OLE at different concentrations $(0,0.5,1,2,4,8$, 16,32 and $64 \mathrm{mg} / \mathrm{ml}$ ). C. glabrata growth was dramatically decreased after treatment with OLE. Light microscopy images were captured at 1,2 and $16 \mathrm{mg} / \mathrm{ml}$ of $211 \mathrm{BC}$ isolate [Figure $3]$. As evident in figure 3, C. glabrata cells were killed after $24 \mathrm{~h}$ of incubation in $16 \mathrm{mg} / \mathrm{ml}$ of OLE. Deduced MIC values were ranging from 2 to $8 \mathrm{mg} / \mathrm{ml}$ and MFC values from 16 to $32 \mathrm{mg} /$ $\mathrm{ml}$ [Table 2].

\section{Anti-virulence activity of olive leaf extract against clinical isolates of $C$. glabrata}

OLE was further assessed for their anti-virulence activity at sub-MICs (0.25xMICs) against the strains C. glabrata ATCC90020, 211BC, 636BC, 603BC, 362BC, 375VVC and 51VVC. According to the $\mathrm{Pz}$ values, there was a significant decrease $(p<0.05)$ in the production of extracellular hydrolases by $C$. glabrata strains treated with and without OLE. 
At $0.25 \times$ MIC tested concentration, OLE was able to reduce in vitro proteinase production by an average of $55.87 \%$, the phospholipase activity by $46.85 \%$ and haemolysin activity by $25.37 \%$ (Table 3). Maximal reducing activity was observed against C. glabrata ATCC90020 with $81.8 \%$ of protease activity and the minimal was almost $4 \%$ for phospholipase activity against 636BC isolates [Table 3].

As presented in Figure 4, the biofilm formation by C. glabrata isolates was significantly decreased in the presence of increasing concentration of OLE. Biofilm formation in both tested strains was reduced. At $0.25 \times$ MIC of OLE, an amount of 2.43 to $39.13 \%$ formation of biofilm was recorded in tested strains. Whereas fluconazole at $0.25 \times$ MIC led to $47.62 \%$ formation of biofilm in C. glabrata $362 \mathrm{HC}, 52.7 \%$ of phospholipase activity, $53 \%$ of protease activity and $35.2 \%$ of haemolysin activity.

\section{Discussion}

Our data has highlighted the production of proteinase, phospholipase and haemolysin in the C. glabrata strains irrespective of their source of clinical isolation. The identification
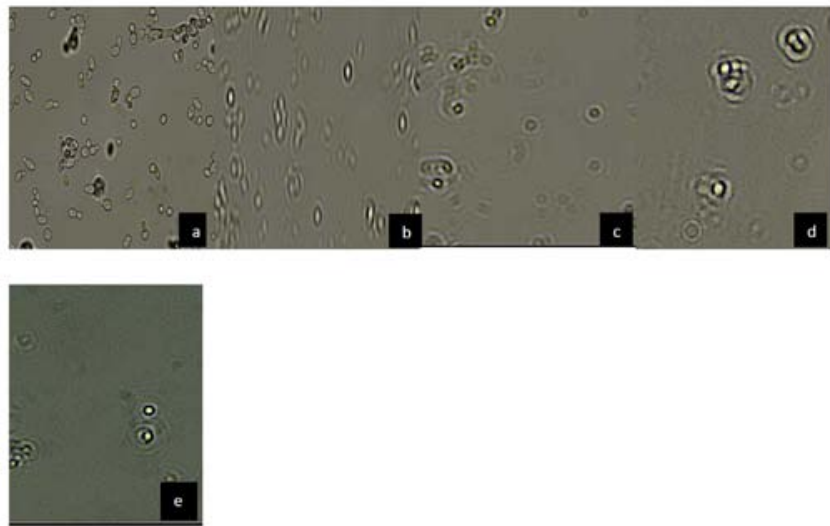

Figure 3: Light microscopy (magnification, $\mathrm{x} 40$ ) images corresponding to the activity of Olive leaves extract against Candida glabrata. Negativecontrol C.glabrata in YPG meduim without any drugs at $24 \mathrm{~h}(\mathrm{a})$ and C.glabrata in DMSO ( $1 \%$ ) at $24 \mathrm{~h}$ (b). Treated cells with $1 \mathrm{mg} / \mathrm{ml}$ (c), 2 $\mathrm{mg} / \mathrm{ml}(\mathrm{d})$ and $16 \mathrm{mg} / \mathrm{ml} \mathrm{(e)} \mathrm{of} \mathrm{the} \mathrm{chemlali} \mathrm{variety} \mathrm{olive} \mathrm{leaves} \mathrm{at} 24 \mathrm{~h}$. Candida growth was dramatically decreased after treatment.

Table 2: The minimal inhibition concentration $\left(\mathrm{MIC}_{50} / \mathrm{MIC}_{90} / \mathrm{MFC}\right)$ of olive leaf extracts against some isolates.

\begin{tabular}{|l|l|l|l|l|}
\hline Isolates n & Source & $\begin{array}{l}\mathbf{M I C}_{\mathbf{5 0}} \mathbf{( m g} / \\
\mathbf{m l})\end{array}$ & $\begin{array}{l}\mathbf{M I C}_{\mathbf{9 0}} \mathbf{( m g} / \\
\mathbf{m l})\end{array}$ & $\begin{array}{l}\text { MFC (mg/ } \\
\mathbf{m l})\end{array}$ \\
\hline $\begin{array}{l}\text { Reference } \\
\text { strain }\end{array}$ & $\begin{array}{l}\text { C. glabrata } \\
\text { ATCC90020 }\end{array}$ & 4 & 8 & 32 \\
\hline $\mathbf{2 1 1 B C}$ & Blood culture & 0.5 & 4 & 32 \\
\hline $\mathbf{6 0 3 B C}$ & Blood culture & 0.5 & 2 & 16 \\
\hline $\mathbf{5 1} \mathbf{~ V V C}$ & vaginal & 0.5 & 4 & 64 \\
\hline 362BC* & Blood culture & 0.5 & 8 & 32 \\
\hline 636BC & Blood culture & 0.5 & 4 & 8 \\
\hline
\end{tabular}

$*$ MIC (fluconazole) $362 \mathrm{BC}=256 \mu \mathrm{g} / \mathrm{ml}$; all others isolates were susceptible; BC: Blood Culture; VVC: Vulvovaginal Candidiasis
Table 3: Comparative analysis of enzymatic activities and inhibition rate for treated and untreated with olive leaves extract in some isolates of $C$. glabrata susceptible or resistant to fluconazole.

\begin{tabular}{|c|c|c|c|c|c|}
\hline \multirow[b]{2}{*}{$\begin{array}{l}\text { Virulence } \\
\text { factors }\end{array}$} & \multirow[b]{2}{*}{ Isolates } & \multicolumn{3}{|c|}{ Antifungal drugs } & \multirow[b]{2}{*}{$\begin{array}{l}\text { Student } \\
\text { test }\end{array}$} \\
\hline & & $\begin{array}{l}0.25 \text { MIC } \\
\text { olive } \\
\text { leaves } \\
\text { extract }\end{array}$ & $\begin{array}{l}\text { Without } \\
\text { any drugs }\end{array}$ & $\begin{array}{l}\text { Inhibition } \\
\text { rates (\%) }\end{array}$ & \\
\hline \multirow{5}{*}{ 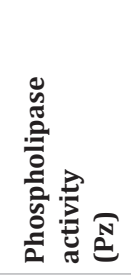 } & $362 \mathrm{HC}$ & 0.86 & 0.48 & 79.17 & \\
\hline & $603 \mathrm{HC}$ & 0.89 & 0.64 & 39.06 & $P<0.05$ \\
\hline & $211 \mathrm{HC}$ & 0.9 & 0.54 & 66.67 & \\
\hline & $636 \mathrm{HC}$ & 0.86 & 0.83 & 3.61 & \\
\hline & $\begin{array}{l}\text { C. glabrata } \\
\text { ATCC90020 }\end{array}$ & 0.86 & 0.59 & 45.76 & \\
\hline \multirow{5}{*}{ 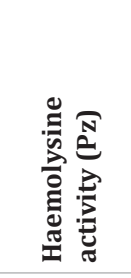 } & $362 \mathrm{HC}$ & 0.84 & 0.62 & 35.48 & \\
\hline & $603 \mathrm{HC}$ & 1 & 0.78 & 28.21 & $P<0.05$ \\
\hline & $211 \mathrm{HC}$ & 0.8 & 0.7 & 14.29 & \\
\hline & $636 \mathrm{HC}$ & 0.8 & 0.58 & 37.93 & \\
\hline & $\begin{array}{l}\text { C. glabrata } \\
\text { ATCC90020 }\end{array}$ & 0.81 & 0.73 & 10.96 & \\
\hline \multirow{5}{*}{ 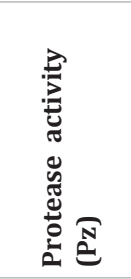 } & $362 \mathrm{HC}$ & 1 & 0.71 & 40.85 & \\
\hline & $603 \mathrm{HC}$ & 1 & 0.64 & 56.25 & \\
\hline & $211 \mathrm{HC}$ & 0.8 & 0.64 & 25 & $P<0.05$ \\
\hline & $636 \mathrm{HC}$ & 1 & 0.57 & 75.44 & \\
\hline & $\begin{array}{l}\text { C. glabrata } \\
\text { ATCC90020 }\end{array}$ & 1 & 0.55 & 81.82 & \\
\hline
\end{tabular}

MIC (FCZ) ${ }_{362}=256 \mu \mathrm{g} / \mathrm{ml}$; MIC (FCZ) ${ }_{603}=2 \mu \mathrm{g} / \mathrm{ml}$; MIC (FCZ) ${ }_{211}=0.25$ $\mu \mathrm{g} / \mathrm{ml}$; MIC (FCZ) ${ }_{636}=1 \mu \mathrm{g} / \mathrm{ml}$; MIC (FCZ) ${ }_{\text {ATC } 990020}=2 \mu \mathrm{g} / \mathrm{ml}$

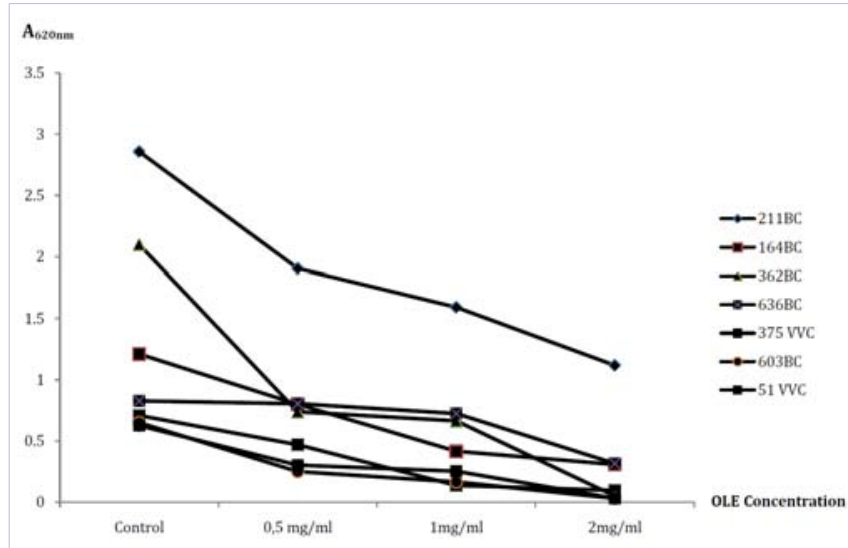

Figure 4: Decreasing biofilm production by selected C. glabrata isolates treated with different concentrations of olive leaves extract.

of these virulence factors unique to $C$. glabrata could provide powerful insights into the pathogenic process and will hopefully reveal novel antifungal drug targets that can be exploited in the search for improved therapies [17]. Extensive research on virulence factors were focused on $C$. albicans. However, quite a few research studies refer to virulence factors production in $C$. glabrata. Most of them have agreed that only a few C. glabrata 
isolates were phospholipase and protease producers and that $C$. albicans is considered as the most pathogenic species [18-20].

Chin, et al. studied the production of phospholipase in 37 strains of Candida and have shown positive activity in $75 \%$ of C. albicans isolates but no C. glabrata strain [18]. However, Ghannoumn, et al. [21] showed that phospholipase activity is considered a rather important activity for candidemia in $C$. glabrata. During our work, all invasive and oral isolates and 95\% of vaginal isolates produced phospholipases. Even though Phospholipase activity does not vary with anatomical location but with geographical origin of isolates [22,23].

In the same way, $96.7 \%$ of isolates from different anatomical sites were protease producers. In contrast, Yamamoto, et al. [24] studied the secretory activity in 52 strains C. glabrata but no strain showed a proteolytic capacity. Seneviratne, et al. [25] evaluated the virulence attribute of Candida bloodstream isolates derived from Hong Kong and Finland and showed that proteinase activity from the finlandais $C$. albicans isolates was significantly higher than the Hong Kong isolates. The variability of virulence factors expression may be explained by possible evolutionary changes in the pathogenic potential of Candida depending on geographic regions [26].

Haemolysin is an enzyme that degrades the erythrocytes of the host, thereby releasing the iron for later use during invasive infections. In our study, all isolates have similar capabilities to produce haemolysin, and like to phospholipase and proteases, haemolysin appears to be an important virulence factor for all $C$. glabrata isolates. Rossoni, et al. tested the haemolysin activity of 50 strains of Candida spp. and found that all strains of C. albicans and $92 \%$ of $C$. glabrata isolates showed hemolytic activity and the level of haemolysin production was significantly higher in $C$. glabrata isolates [27].

All tested isolates showed the same capacity to produce protease, phospholipase and haemolysin and analysis of variance by multifactor ANOVA illustrated that enzymatic activity was not dependent of isolation site $(p \geq 0.05$ ). This observation was dissimilar to the reports given by previous authors whose have concluded that phospholipase and protease production may be used as one of the parameters to distinguish virulent invasive strains from non-invasive colonizers [22]. In fact, many papers confirmed that enzymatic activity of Candida isolates depends also to evolutionary changes that occur between different geographic origins [23-25]

Efficient treatment for fungal infections becomes very important as the frequency of life-threatening fungal diseases is increasing due to the progress in the treatment of critically ill patients whose immune status has been deteriorated. Therefore, the development of novel antifungal agents or strategies that may be effective against pathogens resistant to currently available antifungal drugs is of paramount importance. Considering this, we attempted to investigate concentration dependent effect of Olive Leaves Extract (OLE) against growth and virulence factors production in the fluconazole-resistant or susceptible strains of
C. glabrata. In our study, similar pattern of biofilm formation and enzymes production was also recorded for test leaves and fluconazole drug against C. glabrata 362BC. Comparably to several papers, OLE provides a stronger activity against fungi and parasite [6-8,28-31]. Masoko and makgapeetja when tested 0. Africana extracts against C. albicans and Cryptococcus neoformans demonstrated that both were sensitive to the plant extracts with average MIC values of 0.37 and $0.30 \mathrm{mg} / \mathrm{ml}$ [28].

In our study, OLE exhibited MIC value in the range of 2-8 $\mathrm{mg} / \mathrm{ml}$ against selected isolates. The MIC is greater than that previously described for C. albicans [28]. However, many authors confirmed that the biological activity of plant extract depends on the plant variety and/or extraction procedure which determines the success of isolating compounds from plant material $[28,29]$. Indeed, Markin et al. reported that OLE extracted with water succeeded in elimination of some GRAMbacteria such as Escherichia coli, Pseudomonas aeruginosa and Klebsiella pneumonia with Minimum Bactericidal Concentration (MBC) varied between $0.13 \%$ to $0.6 \%$ and also some yeast such C. albicans with Minimum Fungicidal Concentration (MFC) equal to $15 \%$ [30]. Moreover, Karygianni, et al. [31] demonstrated that OLE extracted with acetone eradicated microbial strains with MIC value between $0.07 \mathrm{mg} / \mathrm{ml}$ for Streptococcus oralis and 10 $\mathrm{mg} / \mathrm{ml}$ for C. albicans and Escherichia coli. In our study, we used methanol to extract compounds from olive leaves which was proven the most polar solvent according to several publications $[29,32]$. The slight difference between the activities of the extracts from many studies could be attributed to the different chemical profile due to plant variety and/or the extraction solvent. Our extract inhibited not only the growth of $C$. glabrata isolates but also the production of virulence factors essentially biofilm formation, production of proteases, phospholipase and haemolysin $(p \leq 0.05)$.

\section{Conclusion}

We conclude that $C$. glabrata isolated from Sfax University Hospital (CHU Habib Bourguiba) presented a high virulent power for studied factors and these activities did not depend on the sampling sites but may be on possible evolutionary changes that may occur between different regions of the world. These results suggested also that extract olive leaves evaluated here is a potential therapeutic drug for the treatment of $C$. glabrata infection. OLE affects not only cellular growth but also cellular adhesion on a solid support and the production of virulence enzymes by $C$. glabrata isolates. Novel therapeutics that target virulence rather than simply in vitro cell growth is of particular interest firstly because of the low sensitivity of $C$. glabrata isolates to azole antifungal drugs and secondly because biofilm formation remains a crucial problem especially in hospitalized patients.

\section{Declarations}

\section{Declaration of interest}

The authors report no conflicts of interest. The authors alone are responsible for the content and writing of the paper. 


\section{Acknowledgement}

This study was financially supported by the Ministry of Higher Education and Scientific Research.

\section{References}

1. Abbes S, Sellami H, Sellami A, Makni F, Mahfoudh N, Makni H, et al. Microsatellite analysis and susceptibility to FCZ of Candida glabrata invasive isolates in Sfax Hospital, Tunisia. Med Mycol. 2011;49(1):105. doi: 10.3109/13693786.2010.493561.

2. Da Silva JFM, De Souza MC, Matta SR, De Andrade MR, Vidal FVN. Correlation analysis between phenolic levels of Brazilian propolis extracts and their antimicrobial and antioxidant activities. Food Chemistry. 2006;99(3):431-435.

3. Tabera J, Guinda A, Ruiz-Rodríguez A, Señoráns FJ, Ibáñez E, Albi T, et al. Countercurrent supercritical fluid extraction and fractionation of high-added-value compounds from a hexane extract of olive leaves. J Agric Food Chem. 2004;52(15):4774-9.

4. Ranalli A, Contento S, Lucera L, Di Febo M, Marchegiani D, Di Fonzo V. Factors affecting the contents of iridoid oleuropein in olive leaves (Olea europaea L). J Agric Food Chem. 2006;54(2):434-40.

5. Paiva-Martins F, Santos V, Mangericão H, Gordon MH. Effects of copper on the antioxidant activity of olive polyphenols in bulk oil and oilin-water emulsions. J Agric Food Chem. 2006;54(10):3738-43.

6. Somova LI, Shode FO, Ramnanan P, Nadar A. Antihypertensive, antiatherosclerotic and antioxidant activity of triterpenoids isolated from Olea europaea, subspecies africana leaves. J Ethnopharmacol. 2003;84(2-3):299-305.

7. Altinyay C, Güvenç A, Altun ML. Antioxidant activities of oleuropein and the aqueous extracts of Olea europaea L. varieties growing in Turkey. Turkish Journal of Pharmaceutical Sciences. 2011;8(1):23-30.

8. Lazzez A, Perri E, Caravita MA, Khlif M, Cossentini M. Influence of Olive Maturity Stage and Geographical Origin on Some Minor Components in Virgin Olive Oil of the Chemlali Variety. J Agric Food Chem. 2008;56(3):982-8. doi: 10.1021/jf0722147.

9. Rauha JP, Remes S, Heinonen M, Hopia A, Kähkönen M, Kujala T, et al. Antimicrobial effects of Finnish plant extracts containing flavonoids and other phenolic compounds. Int J Food Microbiol. 2000;56(1):3-12.

10. Sagdic O, Kuscu A, Ozcan M, Ozcelik S. Effects of Turkish spice extracts at various concentrations on the growth of Escherichia coli 0157:H7 Food Microbiology. 2002;19(5):479-480.

11. Aoki S, Ito-Kuwa S, Nakamura Y, Masuhara T. Comparative pathogenicity of wild type strains and respiratory mutants of Candida albicans in mice. Zentralbl Bakteriol. 1990;273(3):332-43.

12. Price MF, Wilkinson ID, Gentry LO. Plate method for detection of phospholipase activity in Candida albicans. Sabouraudia. 1982;20(1):7-14.

13. Luo G, Samaranayake LP, Yau JY. Candida species exhibit differential in vitro hemolytic activities. J Clin Microbiol. 2001;39(8):2971-4.

14. Silva S, Henriques M, Martins A, Oliveira R, Williams D, Azeredo J. Biofilms of non-Candida albicans Candida species, quantification, structure and matrix composition. Med Mycol. 2009;47(7):681-9. doi: $10.3109 / 13693780802549594$.

15. Karaman I, Sahin F, Güllüce M, Ogütçü H, Sengül M, Adigüzel A. Antimicrobial activity of aqueous and methanol extracts of Juniperus oxycedrus L. J Ethnopharmacol. 2003;85(2-3):231-5.

16. Sahin F, Güllüce M, Daferera D, Sokmen A, Sokmen M, Polissiou M, et al. Biological activities of the essential oils and methanol extract of Origanum vulgare ssp. vulgare in the Eastern Anatolia region of Turkey. Food Control. 2004;15(7):549-557.

17. Morton RD. Aerobic plate count. In, downes FP, Ito K, editors. Compendium of methods for the microbiological examination of foods. $4^{\text {th }} \mathrm{ed}$. American Public Health Association. 2001;69-82.

18. Chin VK, Foong KJ, Maha A, Rusliza B, Norhafizah M, Ng KP, et al. Candida albicans isolates from a Malaysian hospital exhibit more potent phospholipase and haemolysin activities than non-albicans Candida isolates. Trop Biomed. 2013;30(4):654-62.

19. Kumar CP, Kumar SS, Menon T. Phospholipase and proteinase activities of clinical isolates of Candida from immunocompromised patients. Mycopathologia. 2006;161(4):213-8.

20. Tellapragada C, Eshwara VK, Johar R, Shaw T, Malik N, Bhat PV, et al. Antifungal susceptibility patterns, in vitro production of virulence factors, and evaluation of diagnostic modalities for the pathogenic Candida from the blood stream infections and vulvovaginal Candidiasis. J Pathog. 2014;2014:142864. doi: 10.1155/2014/142864.

21. Ghannoum MA. Potential role of phospholipases in virulence and fungal pathogenesis. Clin Microbiol Rev. 2000;13(1):122-43.

22. Kantarcioglu AS, Yücel A. Phospholipase and protease activities in clinical Candida isolates with reference to the sources of strains. Mycoses. 2002;45(5-6):160-5.

23. Borst A, Fluit AC. High levels of hydrolytic enzymes secreted by Candida albicans isolates involved in respiratory infections. J Med Microbiol. 2003;52(Pt 11):971-4.

24. Yamamoto T, Nohara K, Uchida K, Yamaguchi H. Purification and characterization of secretory proteinase of Candida albicans. Microbiol Immunol. 1992;36(6):637-41.

25. Seneviratne CJ, Wong SS, Yuen KY, Meurman JH, Pärnänen P, Vaara M, et al. Antifungal susceptibility and virulence attributes of bloodstream isolates of Candida from Hong Kong and Finland. Mycopathologia. 2011;172(5):389-95. doi: 10.1007/s11046-011-9444-4.

26. Marija B. Oral candidiasis-adhesion of non-albicans Candida species. Proc Nat Sci. 2008;114:69-78.

27. Rossoni RD, Barbosa JO, Vilela SF, Jorge AO, Junqueira JC. Comparison of the hemolytic activity between C. albicans and non-albicans Candida species. Braz Oral Res. 2013;27(6):484-9. doi: 10.1590/S180683242013000600007.

28. Masoko P, Makgapeetja DM. Antibacterial, antifungal and antioxidant activity of Olea africana against pathogenic yeast and nosocomial pathogens. BMC Complement Altern Med. 2015;15:409. doi: 10.1186/ s12906-015-0941-8.

29. Sifaoui I, López-Arencibia A, Martín-Navarro CM, Chammem N, Mejri M, Lorenzo-Morales J, et al. Activity assessment of Tunisian olive leaf extracts against the trophozoite stage of Acanthamoeba. Parasitol Res. 2013;112(8):2825-9. doi: 10.1007/s00436-013-3453-9.

30. Markin D, Duek L, Berdicevsky I. In vitro antimicrobial activity of olive leaves. Mycoses. 2003;46(3-4):132-6.

31. Karygianni L, Cecere M, Skaltsounis AL, Argyropoulou A, Hellwig E, Aligiannis N, et al. High-Level Antimicrobial Efficacy of Representative Mediterranean Natural Plant Extracts against Oral Microorganisms. Biomed Res Int. 2014;2014:839019. doi: 10.1155/2014/839019.

32. Derda M, Hadaś E, Thiem B. Plant extracts as natural amoebicidal agents. Parasitol Res. 2009;104(3):705-8. doi: 10.1007/s00436-0081277-9. 